\title{
Insolation triggered abrupt weakening of Atlantic circulation at the end of interglacials*
}

\author{
Authors: Q.Z. Yin ${ }^{1 *}$, Z.P. Wu ${ }^{1,2}$, A. Berger ${ }^{1}$, H. Goosse ${ }^{1}$, D. Hodell ${ }^{3}$
}

\section{Affiliations:}

${ }^{1}$ Georges Lemaître Center for Earth and Climate Research, Earth and Life Institute, Université catholique de Louvain, Louvain-la-Neuve, Belgium

${ }^{2}$ Key Laboratory of Cenozoic Geology and Environment, Institute of Geology and Geophysics, Chinese Academy of Sciences, Beijing, China

${ }^{3}$ Godwin Laboratory for Palaeoclimate Research, Department of Earth Sciences, University of Cambridge, Cambridge, UK.

*Correspondence to: qiuzhen.yin@uclouvain.be

\begin{abstract}
Abrupt cooling is observed at the end of interglacials in many paleoclimate records, but the mechanism responsible remains unclear. On the basis of model simulations, we demonstrate that there exists a threshold in the level of astronomically-induced insolation below which abrupt changes at the end of interglacials of the last 800,000 years occur. When decreasing insolation reaches the critical value, it triggers a strong abrupt weakening of the Atlantic meridional overturning circulation (AMOC) and a cooler mean climate state accompanied by high-amplitude variations lasting for several thousand years. The mechanism involves sea ice feedbacks in the

20 Nordic and Labrador Seas. The ubiquity of this threshold suggests its fundamental role in terminating the warm climate conditions at the end of interglacials.
\end{abstract}

One Sentence Summary: Astronomically-induced slow variation of insolation triggers abrupt climate changes at the end of interglacials.

\section{Main Text:}

Abrupt climate changes and millennial climate variability have been identified in numerous paleoclimate records, in particular during the last glacial period. Increasingly more studies show that abrupt and millennial-to-centennial scale climate changes can also be found in much older times (1-6) and are a persistent feature at least over the last few million years occurring not only during glacial times but also during interglacials (4,7-11). Many interglacial periods of the late Pleistocene are terminated by an abrupt cooling event that marks the re-appearance of strong millennial variability $(9,12-16)$.

During the last interglacial MIS-5e, the first abrupt cooling characterizing the end of the interglacial is observed in the Greenland ice core records (17), which is defined as Greenland stadial 26 and occurred at about $119 \mathrm{ka} \mathrm{BP}( \pm 2.5 \mathrm{ka})$. A similar abrupt cooling is also found in the

\footnotetext{
* This manuscript has been accepted for publication in Science (doi: 10.1126/science.abg1737). This version has not undergone final editing. Please refer to the complete version of record at http://www.sciencemag.org/. The manuscript may not be reproduced or used in any manner that does not fall within the fair use provisions of the Copyright Act without the prior, written permission of AAAS.
} 
$\delta^{18} \mathrm{O}$ record (5) of the Iberian Margin at $122.4 \mathrm{ka} \mathrm{BP}( \pm 4 \mathrm{ka})$ (Fig. 1$)$, which is consistent with the Greenland ice core records considering the age uncertainty. In fact, this $\delta^{18} \mathrm{O}$ record shows that an abrupt cooling occurs at the end of each interglacial of the last $800 \mathrm{ka}$ (ka: thousand years) (Fig.1), indicating that this is a general feature for all interglacials during the late Pleistocene. After the abrupt cooling, the climate enters into a cold state characterized by increased millennial scale fluctuations.

The observation that a strong abrupt cooling occurs when climate was still in a warm interglacial state is puzzling and its cause remains uncertain. Astronomically-induced long-term variations of insolation is one of the most important external forcings of the climate system. It acts as a pacemaker of climate change driving the behavior of different components of the climate system. Because it varies slowly on the order of tens of thousands of years, it is often ignored in explaining abrupt climate changes on shorter time scales $\left(10^{2}-10^{3}\right.$ years $)$. To investigate the possible influence of the slow variation of insolation on interglacial climate, we performed transient climate simulations for all interglacials of the last $800 \mathrm{ka}$ with an atmosphere-oceanvegetation coupled model, LOVECLIM1.3 (Supplementary Material, hereafter SM). We considered 11 interglacial sub-stages (18): Marine Isotope Stage (MIS)-1, 5e, 7ac, 7e, 9e, 11c, 13a, $15 \mathrm{a}, 15 \mathrm{e}, 17 \mathrm{c}$ and $19 \mathrm{c}$. In order to investigate the influence of insolation alone, only astronomically-induced insolation was initially allowed to vary with time and $\mathrm{CO}_{2}$ concentration was fixed to a typical interglacial level of $280 \mathrm{ppmv}$. In a second set of simulations, the impacts of both $\mathrm{CO}_{2}$ and insolation changes were investigated.

During MIS-5e, in response to the variation of insolation alone, our simulated sea surface temperature (SST) in the northern North Atlantic varies slowly and follows closely the variation of summer insolation (Fig.2c). However, an abrupt SST decrease $\left(1.4^{\circ} \mathrm{C}\right.$ in about 50 years) occurs at $119.4 \mathrm{ka} \mathrm{BP}$, and it is followed by rapid and large oscillations over the next 7000 years with a much cooler mean climate state. Similar oscillations happen in the simulated surface air temperature (SAT), precipitation and vegetation in different latitudes especially in the northern hemisphere (NH) (Fig. S1), indicating that these abrupt oscillations are a widespread phenomenon.

During the abrupt cooling at $119.4 \mathrm{ka} \mathrm{BP}$, the oceans become cooler in the NH especially in the northern North Atlantic where the cooling can reach $1^{\circ} \mathrm{C}-5^{\circ} \mathrm{C}$ (Fig.2d), and they become slightly warmer in the southern hemisphere $(\mathrm{SH})$. The change in surface air temperature (SAT) (Fig.2e) has a similar pattern but with a larger amplitude than SST. Over the Labrador Sea and the Barents Sea, the SAT decreases by up to $6^{\circ} \mathrm{C}$ and $4^{\circ} \mathrm{C}$, respectively. It decreases by $5^{\circ} \mathrm{C}$ over southern Greenland. The opposite change in temperature in the two hemispheres is associated with an abrupt weakening of AMOC (a weakening of $30 \%$ in 50 years) (Fig.2b) which is followed by large-amplitude oscillations with a mean state of much weaker AMOC. The mechanism by which AMOC influences the climate in both hemispheres has been discussed in numerous studies (19). Stronger AMOC transports more heat to the NH high latitudes leading to a generally warmer $\mathrm{NH}$ and cooler SH, and vice versa. The abrupt weakening of AMOC at $119.4 \mathrm{ka}$ is responsible for a reduction of $22 \%$ in the northward heat transport across $40^{\circ} \mathrm{N}$ in the North Atlantic. Therefore, the 40 key to understanding the insolation-induced abrupt changes in our simulated temperature and other components of the climate system is how insolation induces such abrupt changes in AMOC.

The occurrence of abrupt weakening of AMOC followed by high-amplitude oscillations driven by slow insolation changes only is unexpected. It occurs not only during MIS-5e, but also during all the other interglacials except MIS-1, MIS-9e and MIS-19 (Fig.S2). The onset of the oscillations is always marked by a sharp weakening of AMOC that happens at the end of the 
interglacials. Moreover, the onset always occurs at times when NH summer insolation is decreasing and approaching a minimum. This leads to the proposition that a threshold of $\mathrm{NH}$ summer insolation may trigger an abrupt weakening of the AMOC. Our examination suggests that the threshold value is not exactly the same among the interglacials (Fig.S3). This is not unexpected because the latitudinal and seasonal distribution of insolation is not exactly the same among the interglacials. Nevertheless, our results show that, to trigger the abrupt weakening of AMOC, the summer insolation must be sufficiently low, ranging in a narrow window between $352.1 \mathrm{Wm}^{-2}$ for MIS-15e and 358.2 $\mathrm{Wm}^{-2}$ for MIS-7a (Fig.3, Fig.S3).

The mean summer insolation is controlled by both obliquity and precession with precession being the major controlling factor reflecting the important role of the length of the season. Our results (Fig.S2) show that the favorable astronomical condition to trigger the abrupt weakening of AMOC is a combination of a high precession with June solstice occurring at aphelion (inducing long summers) and, at the same time, a relatively low obliquity (inducing low total summer irradiation). The insolation threshold values have a strong negative correlation with the precession index (Fig.S3) due to the dominance of precession on the mean summer insolation. Obliquity also plays a role through its phase relationship with precession. For all the interglacials, when abrupt weakening and high-amplitude oscillations of AMOC occur, precession maxima and obliquity minima are in phase (Fig.S2), leading to very low summer insolation in the NH. On the contrary, for some periods such as around 210 and $495 \mathrm{ka} \mathrm{BP}$, although precession reaches one of its maxima, abrupt oscillations do not occur owing to the anti-phase relationship between precession and obliquity. In this case, high obliquity counteracts the effect of high precession making the summer insolation insufficiently low. During MIS-1 and MIS-19, low eccentricity leads to small variations in precession and therefore there is no deep minima in summer insolation, explaining why insolation alone does not trigger abrupt oscillations during these two interglacials. Although MIS-11 also has low eccentricity similar to MIS-1 and 19, the insolation is sufficiently low to trigger abrupt oscillations because of the low obliquity. In summary, to have abrupt weakening of AMOC, both low obliquity and high precession (occurrence of NH summer at aphelion and high eccentricity) are required.

Comparison between our two sets of simulations shows that lowered insolation is essential for triggering the abrupt changes of $\mathrm{AMOC}$ at the end of interglacials, and $\mathrm{CO}_{2}$ only modulates slightly the effect of insolation (SM and Fig.S2). For MIS-9e and MIS-19 when insolation minima are insufficiently low to trigger the abrupt oscillations, the decrease of $\mathrm{CO}_{2}$ reinforces the insolation-induced cooling and helps to trigger abrupt oscillations.

Figure 1 shows that under the combined influence of insolation and $\mathrm{CO}_{2}$, our model simulates an abrupt weakening of AMOC at the end of all the interglacials of the last $800 \mathrm{ka}$. Their timings are in good agreement with those of the first abrupt cooling in the planktic $\delta^{18} \mathrm{O}$ record from the Iberian Margin if age uncertainties are considered, except for MIS-13a that is a controversial interglacial (20). After this time, the climate becomes unstable in both the simulation and the planktic $\delta^{18} \mathrm{O}$ record. The first sudden cooling and reduction of AMOC at $119.8 \mathrm{ka} \mathrm{BP}$ in 40 our last interglacial simulation also coincide with the first abrupt cooling observed at $119 \mathrm{ka}$ BP (the stadial 26) in the Greenland ice core records (17) and around $118 \mathrm{ka} \mathrm{BP}$ in the SST in subpolar North Atlantic (12). It is worth noting that a series of cooling events occurring after MIS-5e have been observed in many records, and our simulated abrupt cooling corresponds to the very first cooling just after the interglacial optimum (SM). The SST reconstructions south of Greenland indicate a sudden cooling around 119, 238, 322 and $399 \mathrm{ka} \mathrm{BP}$ at the end of MIS-5e, 7e, 9e and 
and 11c (14). At the end of MIS-11c, an abrupt weakening of the Asian monsoon is indicated around $397 \mathrm{ka}$ BP (9) and an abrupt cooling around $396 \mathrm{ka} \mathrm{BP}$ is identified in the Lake Baikal region (16). All these dates are consistent with the ages for each of the first abrupt AMOC weakening in our simulations, marking the end of the interglacials (Fig.1) when age uncertainties are taken into account. The consistency between our model results and paleoclimate records suggests that the abrupt cooling at the end of interglacials occurred when insolation fell below the threshold value, and this consistency also supports the validity of the range of the insolation threshold values found in our study (Fig.3).

In addition to the end of interglacials, there were other times in the last $800 \mathrm{ka}$ when insolation fell below the threshold (Fig.3). Most occurred during glacial times, and two during the stadials MIS-13b and MIS-15b. However, given the very different conditions during glacial times with much larger ice sheets and lower $\mathrm{CO}_{2}$, the insolation threshold value determined from our interglacial climate simulations is most likely not the same for glacial times. Regarding the future, our simulation for the next 34 ka does not show abrupt change of AMOC (Fig.S2). The insolation minima remain high during the next $50 \mathrm{ka}$ due to a small eccentricity, and it reaches the threshold only at $50 \mathrm{ka}$ AP (Fig.3). Such a long period without insolation reaching the threshold is very exceptional as compared to all the interglacials in the last $800 \mathrm{ka}$, including MIS-11 and MIS-19 which also have small eccentricity. Actually, it has been demonstrated that the current interglacial would be exceptionally long and the next glacial inception would occur only in 50,000 years (22).

To explain how slow variation of insolation alone triggers abrupt weakening and highamplitude oscillations of AMOC, we use the example case of MIS-5e. The processes are similar for other interglacials. Fig.4a shows that the strength of the AMOC is anti-correlated with summer insolation on time scales of orbital variations. A previous study (21) showed that over the highlatitude oceans, summer insolation plays a key role not only in controlling summer SST and sea ice, but also during the winter through the remnant effects of summer insolation. Our analyses show that this anti-phase relationship between summer insolation and the intensity of AMOC can be explained by the fact that, when insolation decreases, the SST in the northern North Atlantic decreases and more sea ice is formed leading to saltier surface water as a consequence of brine rejection. In addition, the net precipitation over the ocean south of Greenland decreases significantly leading to additional salinity increase. Lower SST and saltier water combine to contribute to denser surface water, stronger convection, and stronger AMOC.

The smooth relationship between summer insolation and AMOC described above is disrupted by abrupt oscillations in AMOC as soon as insolation decreases below the threshold value. During the normal AMOC state (Fig.4a, point A), deep mixing in the North Atlantic occurs at two centers, the southern Labrador Sea and the Nordic Sea (Fig.4d). The intensity of AMOC is controlled by convection over these two regions. In the northern (N.) Nordic Sea, before $122 \mathrm{ka}$ BP (Fig.4b, point B), the convection intensifies smoothly with decreasing insolation. However, starting from $122 \mathrm{ka} \mathrm{BP}$, it weakens smoothly in spite of continuously decreasing insolation and then, starting around $119 \mathrm{ka}$ BP, multi-centennial scale high-amplitude variations occur. In the 40 Labrador Sea, the intensification of convection is accelerated from $122 \mathrm{ka}$ BP but is suddenly shutdown at $119.4 \mathrm{ka} \mathrm{BP}$ (Fig. 4b, point C) and remains inactive over the next 7000 years. These results show that the abrupt weakening in AMOC at $119.4 \mathrm{ka} \mathrm{BP}$ is caused by the sudden shutdown of convection in the Labrador Sea, whereas the high-amplitude variability of AMOC between 119 and $112 \mathrm{ka} \mathrm{BP}$ is related to changes in the N. Nordic Sea. 
The changes in the convection in the Labrador Sea and N. Nordic Seas are closely linked to the changes in sea ice over these regions. Over the southern Labrador Sea there is no sea ice before $122 \mathrm{ka} \mathrm{BP}$ owing to the relatively high summer insolation (Fig.4c and 4e). Because of the cooling induced by decreasing insolation, sea ice starts to develop there at $122 \mathrm{ka} \mathrm{BP} \mathrm{(Fig.} \mathrm{4c).}$ The appearance of sea ice amplifies and accelerates the cooling over the Labrador Sea which explains the accelerated deepening of convection after $122 \mathrm{ka} \mathrm{BP}$ (Fig. $4 \mathrm{~b}$ up to point C). Sea ice continues to grow and starts to cover the center of convection in the Labrador Sea at $119.4 \mathrm{ka} \mathrm{BP}$ (Point C, Fig.4f), leading finally to a sharp shutdown of convection and a complete coverage of sea ice in the Labrador Sea only in a few decades (Fig.4g).

In the N. Nordic Sea, before $122 \mathrm{ka} \mathrm{BP}$, the convection is mainly controlled by the gradual cooling related to decreasing insolation, which explains the gradual intensification of convection. With insolation continuing to drop, cooling intensified, Arctic sea ice extended southwards and started to cover the convection center in the N. Nordic Sea by 122 ka BP (Fig. 4e), which explains the weakening of N. Nordic convection starting from this time (Fig. 4b). This lasts until $119 \mathrm{ka} \mathrm{BP}$ with no abrupt weakening as seen in the Labrador Sea but immediately followed by high-amplitude multi-centennial oscillations.

These multi-centennial oscillations in the convection of the N. Nordic Sea can be explained by the feedbacks between sea ice and ocean temperature. To illustrate this effect, we focus on three cycles. When sea ice increases over the N. Nordic Sea, the convection is weakened and becomes inactive when sea ice reaches its maximum and covers almost completely the convection center in N. Nordic Sea (Fig.S4a, phase A and Fig. S4b-c). This convection-inactive period lasts for about 70 years. In the meantime, convection nevertheless remains active in the southern Nordic Sea (Fig. $\mathrm{S} 4 \mathrm{c}$ ) because this region is not covered by sea ice. This explains why AMOC is not completely shut down although the convection in both the Labrador Sea and the N. Nordic Sea is inactive during phase A. When sea ice covers completely the N. Nordic Sea, the sub-surface ocean temperature increases (Fig. S4a, phase A) because increased sea ice cover leads to reduced ocean heat loss to the atmosphere and consequently more heat stored in the ocean, resulting in subsurface warming. The ocean heat accumulates with time and it melts sea ice and warms the air. The rapid release of heat from ocean to atmosphere after a rather long period of heat accumulation explains the sudden decline of sea ice at the end of phase A (Fig. S4a). In the meantime, sub-surface ocean temperature decreases rapidly. Once sea ice retreats from the convection site in the N. Nordic Sea, deep mixing starts again and convection is switched on (phase B, Fig.S4a and 4d), which leads to the intensification of AMOC. The intensification of AMOC in turn enhances the northward oceanic heat transport which explains the rapid sub-surface warming in the N. Nordic Sea after the rapid cooling at the end of phase A. However, as insolation remains very low, the background climate is still too cold, and thus the Arctic sea ice extends again to the south and covers the convection center in the N. Nordic Sea. This leads to a new cycle of the multi-centennial oscillations (Fig.S4a).

The high-amplitude oscillations of AMOC only stop when insolation becomes high enough such that sea ice no longer covers the convection centers of the N. Nordic Sea and Labrador Sea. The duration of the high-amplitude oscillations differs among interglacials and ranges from 3100 years for MIS-11c to 8000 years for MIS-7ac and -7e (Fig.S2). The duration is related to the length of the intervals over which insolation is lower than the threshold value. During these periods, AMOC varies at multi-century scale with a major periodicity between 300 and 600 years. 
The good agreement in the timing of the first cooling at the end of the interglacials between various paleoclimate records and our model results supports an insolation threshold associated with the resumption of millennial variability near the end of all interglacial periods. The insolationinduced abrupt weakening of AMOC happens at the end of the interglacials during which time the $\mathrm{CO}_{2}$ concentration is still relatively high and ice sheets are relatively small. The millennial event triggered by declining insolation may very well lead to the end of interglacial conditions, as it results in a strong abrupt cooling and a cold mean climate state lasting for several thousands of years in the northern middle-high latitudes and high snow accumulation over ice sheet nucleation regions $(\mathrm{SM})$. These conditions are favorable for ice sheet growth that, in turn, amplify the cooling and definitively terminate the warm interglacial period.

\section{References and Notes:}

1. J. Jouzel, V. Masson-Delmotte, O. Cattani, G. Dreyfus, S. Falourd, G. Hoffmann, B. Minster, J. Nouet, J. M. Barnola, J. Chappellaz, H. Fischer, J. C. Gallet, S. Johnsen, M. Leuenberger, L. Loulergue, D. Luethi, H. Oerter, F. Parrenin, G. Raisbeck, D. Raynaud, A. Schilt, J. Schwander, E. Selmo, R. Souchez, R. Spahni, B. Stauffer, J. P. Steffensen, B. Stenni, T. F. Stocker, J. L. Tison, M. Werner, E. W. Wolff, Orbital and millennial Antarctic climate variability over the past 800,000 years. Science 317, 793-796 (2007).

2. K.A. Gibson, L.C. Peterson, A 0.6 million year record of millennial - scale climate variability in the tropics. Geophys. Res. Lett. 41 (3), 969-975 (2014).

3. H. Cheng, P. Z. Zhang, C. Spötl, L. Edwards, Y. J. Cai, D. Z. Zhang, W. C. Sang, M. Tan, Z. S. An, The climatic cyclicity in semiarid-arid central Asia over the past 500,000 years. Geophys. Res. Lett. 39, L01705 (2012).

4. B. Martrat, J. O. Grimalt, C. Lopez-Martinez, I. Cacho, F. J. Sierro, J. Flores, R. Zahn, M. Canals, J. H. Curtis, D. A. Hodell, Abrupt temperature changes in the Western Mediterranean over the past 250,000 years. Science 306, 1762-1765 (2004).

5. D. A. Hodell, L. Lourens, S. Crowhurst, T. Konijnendijk, R. Tjallingii, F. Jiménez-Espejod, L. Skinnera, P. C. Tzedakise, A reference time scale for Site U1385 (Shackleton Site) on the SW Iberian Margin. Glob. Planet. Change 133, 49-64 (2015).

6. B. Birner, D. A. Hodell, P. C. Tzedakis, L. C. Skinner, Similar millennial climate variability on the Iberian margin during two early Pleistocene glacials and MIS 3. Paleoceanography 31, 203-217 (2016).

7. E. Palumbo, J. A. Flores, C. Perugia, Z. Petrillo, A. H. L. Voelker, F. O. Amore, Millennial scale coccolithophore paleoproductivity and surface water changes between 445 and $360 \mathrm{ka}$ (Marine Isotope Stages 12/11) in the Northeast Atlantic. Paleogeogr. Paleoclimatol. Paleoecol. 383, 27-41 (2013).

8. P. C. Tzedakis, R. N. Drysdale, V. Margari, L. C. Skinner, L. Menviel, R. H. Rhodes, A.S. Taschetto, S.J. Crowhurst, J.C. Hellstrom, A.E. Fallick, J.O. Grimalt, J.F. McManus, B. Martrat, Z. Mokeddem, F. Parrenin, E. Regattieri, K. Roe and G. Zanchetta, Enhanced climate instability in the North Atlantic and southern Europe during the Last Interglacial. Nat. Commun. 9, 1-14 (2018).

9. X. N. Zhao, H. Cheng, A. Sinha, H. W. Zhang, J. L. Baker, S. Chen, X. G. Kong, Y. J. Wang, R. L. Edwards, Y. F. Ning, J. Y. Zhao, A high-resolution speleothem record of marine isotope stage 11 as a natural analog to Holocene Asian summer monsoon variations. Geophys. Res. Lett. 46, L083836 (2019). 
10. E. V. Galaasen, U. S. Ninnemann, A. Kessler, N. Irval1, Y. Rosenthal, J. Tjiputra, N. Bouttes, D. M. Roche, H. F. Kleiven, D. A. Hodell, Interglacial instability of North Atlantic Deep Water ventilation. Science 367, 1485-1489 (2020).

11. C. Nehrbass-Ahles, J. Shin, J. Schmitt, B. Bereiter, F. Joos, A. Schilt, L. Schmidely, L. Silva, G. Teste, R. Grilli, J. Chappellaz, D. A. Hodell, H. Fischer, T. F. Stocker, Abrupt $\mathrm{CO}_{2}$ release to the atmosphere under glacial and early interglacial climate conditions. Science 369, 10001005 (2020)

12. D. W. Oppo, J. F. McManus, J. L. Cullen, Evolution and demise of the Last Interglacial warmth in the subpolar North Atlantic. Quat. Sci. Rev. 25, 3268-3277 (2006).

13. Z. Mokeddem, J. F. McManus, D. W. Oppo, Oceanographic dynamics and the end of the last interglacial in the subpolar North Atlantic. Proc. Natl. Acad. Sci. U.S.A. 111, 11263-11268 (2014).

14. N. Irvali, E.V. Galaasen, U.S. Ninnemann, Y. Rosenthal, A. Born, H.F. Kleiven, A low climate threshold for south Greenland Ice Sheet demise during the Late Pleistocene. PNAS, 2020, 117(1), 190-195 (2020).

15. E. V. Galaasen, U. S Ninnemann, N. Irvali, H. F. Kleiven, C. Kissel, D.A. Hodell, Rapid reductions in North Atlantic Deep Water during the peak of the last interglacial period. Science 343, 1129-1132 (2014).

16. A. A. Prokopenko, E. V. Bezrukova, G. K. Khursevich, E. P. Solotchina, M. I. Kuzmin, P. E. Tarasov, Climate in continental interior Asia during the longest interglacial of the past 500000 years: the new MIS 11 records from Lake Baikal, SE Siberia. Clim. Past 6, 31-48 (2010).

17. North Greenland Ice Core Project Members, High-resolution climate record of the Northern Hemisphere back into the last interglacial period. Nature 431,147-151 (2004).

18. Past Interglacials Working Group of PAGES, Interglacials of the last 800,000 years. Rev. Geophys. 54, 162-219 (2016).

19. S. Rahmstorf, Ocean circulation and climate during the past 120,000 years. Nature 419, 207217 (2002).

20. Z. T. Guo, A. Berger, Q. Z. Yin, L. Qin, Strong asymmetry of hemispheric climates during MIS-13 inferred from correlating China loess and Antarctica ice records. Clim. Past. 5, 21-31 (2009).

21. Q. Z. Yin, A. Berger, Individual contribution of insolation and $\mathrm{CO}_{2}$ to the interglacial climates of the past 800,000 years. Clim. Dyn. 38, 709-724 (2012).

22. A. Berger, M.F. Loutre, An Exceptionally Long Interglacial Ahead? Science 297, 1287-1288 (2002).

23. A. Berger, M. F. Loutre, Insolation values for the climate of the last 10 million years. Quat. Sci. Rev. 10, 297-317 (1991).

24. A. Berger, M. F. Loutre, Q. Z. Yin, Total irradiation during any time interval of the year using elliptic integrals. Quat. Sci. Rev. 29, 1968-1982 (2010).

25. A. Berger, Q. Z. Yin, "Astronomical theory and orbital forcing" in The Sage handbook of environmental change, J. A. Matthews, P. J. Bartlein, K. R. Briffa, A. G. Dawson, A. de Vernal, T. Denham, S. C. Fritz, F. Oldfield, Eds. (SAGE London, 2012), pp. 405-425.

26. H. Goosse, V. Brovkin, T. Fichefet, R. Haarsma, P. Huybrechts, J. Jongma, A. Mouchet, F. Selten, P.-Y. Barriat, J.-M. Campin, E. Deleersnijder, E. Driesschaert, H. Goelzer, I. Janssens, M.-F. Loutre, M.A. Maqueda, T. Opsteegh, P.-P. Mathieu, G. Munhoven, E.J. Pettersson, H. Renssen, D.M. Roche, M. Schaeffer, B. Tartinville, A. Timmermann, S.L. Weber, Description 
of the Earth system model of intermediate complexity LOVECLIM version 1.2. Geosci. Model Dev. 3, 603-633 (2010).

27. M. F. Loutre, T. Fichefet, H. Goosse, P. Huybrechts, H. Goelzer, E. Capron, Factors controlling the last interglacial climate as simulated by LOVECLIM1.3. Clim. Past 10, 1541-1565 (2014).

28. A. Barthélemy, H. Goosse, P. Mathiot, T. Fichefet, Inclusion of a katabatic wind parameterization in a coarse-resolution global coupled climate model. Ocean Modell. 48, 4554 (2012).

29. R. J. Stouffer, J. Yin, J. M. Gregory, K. W. Dixon, M. J. Spelman, W. Hurlin, A. J. Weaver, M. Eby, G. M. Flato, H. Hasumi, A. Hu, J. H. Jungclaus, I. V. Kamenkovich, A. Levermann, M. Montoya, S. Murakami, S. Nawrath, A. Oka, W. R. Peltier, D. Y. Robitaille, A. Sokolov, G. Vettoretti, Investigating the causes of the response of the thermohaline circulation to past and future climate changes. J. Clim. 19, 1365-1387 (2006).

30. T. Friedrich, A. Timmermann, L. Menviel, O. Elison Timm, A. Mouchet, D. M. Roche, The mechanism behind internally generated centennial-to-millennial scale climate variability in an earth system model of intermediate complexity. Geosci. Model Dev. 3, 377-389 (2010).

31. A. Kessler, N. Bouttes, D. M. Roche, U. S. Ninnemann, J. Tjiputra, Dynamics of spontaneous (multi) centennial-scale variations of the Atlantic Meridional Overturning circulation strength during the Last Interglacial. Paleoceanography and Paleoclimatology 35, PA003913 (2020).

32. D. Luthi, M. L. Floch, B. Bereiter, T. Blunier, J. M. Barnola, U. Siegenthaler, D. Raynaud, J. Jouzel, H. Fischer, K. Kawamura, T. F. Stocker, High-resolution carbon dioxide concentration record 650,000-800,000 years before present. Nature 453, 379-382 (2008).

33. L. Loulergue, A. Schilt, R. Spahni, V. Masson-Delmotte, T. Blunier, B. Lemieux, J. M. Barnola, D. Raynaud, T. F. Stocker, J. Chappella, Orbital and millennial-scale features of atmospheric $\mathrm{CH}_{4}$ over the past 800,000 years. Nature 453, 383 (2008).

34. A. Schilt, M. Baumgartner, T. Blunier, J. Schwander, R. Spahni, H. Fischer, T. F. Stocker, Glacial-interglacial and millennial-scale variations in the atmospheric nitrous oxide concentration during the last 800,000 years. Quat. Sci. Rev. 29, 182-192 (2010).

35. J.I. Svendsen, H. Alexanderson, V.I. Astakhov, I. Demidov, J.A. Dowdeswell, S. Funder, V. Gataulling, M. Henriksen, C. Hjort, M. Houmark-Nielsen, H.W. Hubberten, Ó. Ingólfsson, M. Jakobsson, K.H. Kjær, E. Larsen, H. Lokrantz, J. P. Lunkka, A. Lyså, J. Mangerud, A. Matiouchkov, A. Murray, P. Möller, F. Niessen, O. Nikolskaya, L. Polyak, M. Saarnisto, C. Siegert, M.J. Siegert. R.F. Spielhagen, R. Steins, Late Quaternary ice sheet history of northern Eurasia. Quaternary Science Reviews 23, 1229-1271 (2004).

36. C.R. Stokes, L. Tarasov, A.S. Dyke, Dynamics of the North American Ice Sheet Complex during its inception and build-up to the Last Glacial Maximum. Quaternary Science Reviews, 50, 86-104 (2012).

37. A. Ganopolski, R. Calov, M. Claussen, Simulation of the last glacial cycle with a coupled climate ice-sheet model of intermediate complexity. Climate of the Past 6, 229-244 (2010).

$40 \quad$ Stat. Assoc. 74 (368), 829-836 (1979).

Acknowledgments: Computational resources have been provided by the supercomputing facilities of the Universite catholique de Louvain (CISM/UCL) and the Consortium des Équipements de Calcul Intensif en Fédération Wallonie Bruxelles (CÉCI) funded by the Fond de la Recherche Scientifique de Belgique (F.R.S.-FNRS) under convention 2.5020.11. Z.P.W. acknowledges the support of F.R.S.-FNRS under grant MIS F.4529.18 and the National Natural 
Science Foundation of China (Grant Nos. 41690114 and 41888101) for his doctoral study. Q.Z.Y. is Research Associate and H.G. is Research Director of F.R.S.-FNRS.

Funding: This work is supported by the Fonds de la Recherche Scientifique-FNRS under grant MIS F.4529.18.

Author contributions: Q.Z.Y. designed the study and wrote the first draft of the paper. Q.Z.Y. and Z.P.W. performed model simulations and analyzed model results. D.H. provided the planktonic $\delta^{18} \mathrm{O}$ data. All authors contributed to the discussion and writing of the final paper.

Competing interests: Authors declare no competing interests.

Data and materials availability: The code of LOVECLIM1.3 is available at www.climate.be/loveclim. The planktonic $\delta^{18} \mathrm{O}$ data used in this study are available in the Supplementary materials.

\section{Supplementary Materials:}

Supplementary text

Figs. S1 to S6

15

References (26-38)

Supplementary data 

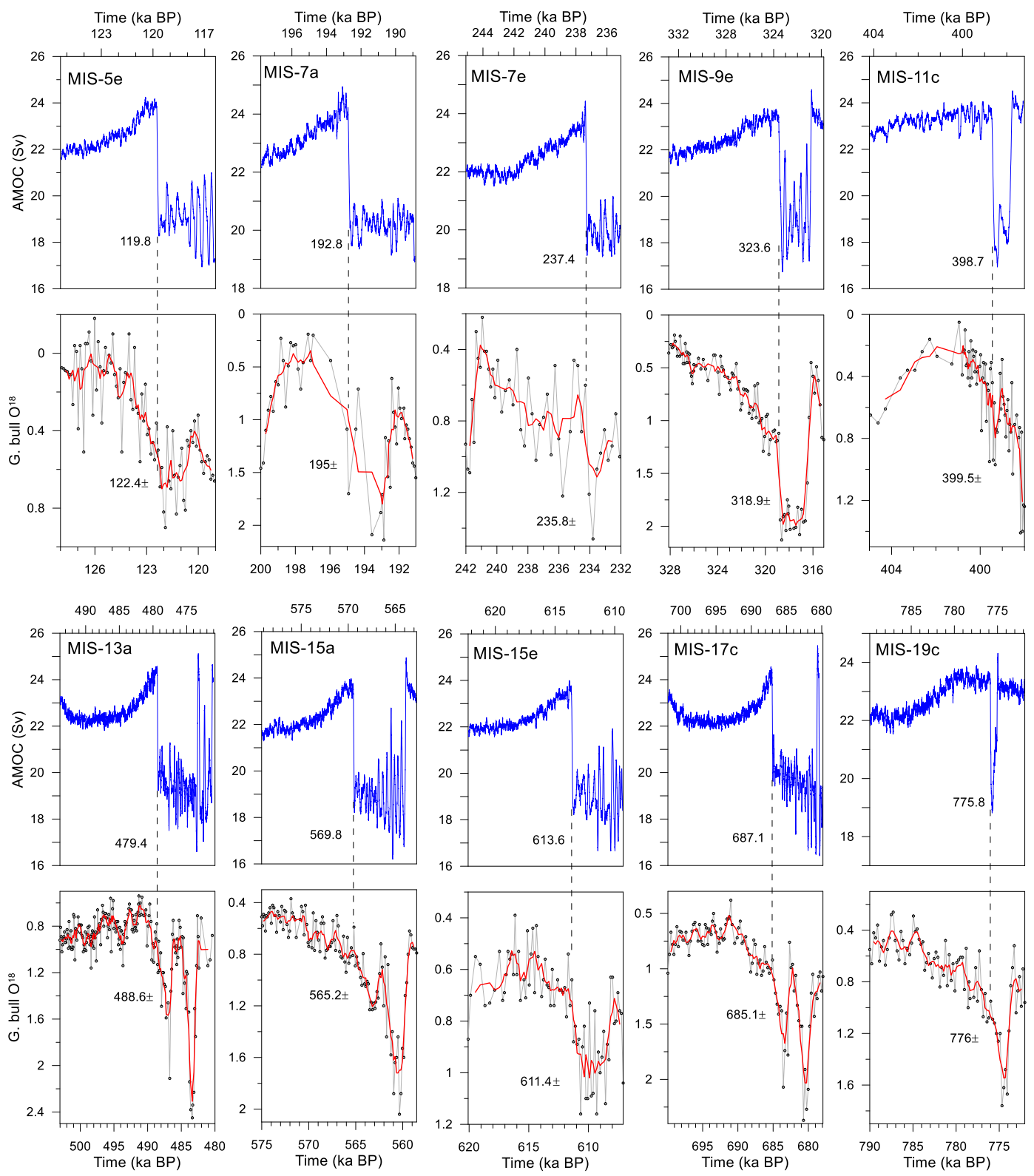

Fig. 1. The planktonic $\delta^{18} \mathrm{O}$ record from the Iberian margin and the simulated AMOC intensity (blue). The $\delta^{18} \mathrm{O}$ data are from ref. (5) augmented in this study by additional analyses over during glacial inceptions. Gray dotted lines and red lines represent the $\delta^{18} \mathrm{O}$ data and a five-point running mean of the data. The AMOC results are from the second set of simulations driven by both insolation and $\mathrm{CO}_{2}$, and 100-year running mean is applied. The dates of the abrupt cooling and abrupt weakening of AMOC are indicated. Given the age uncertainty ( $\pm 4 \mathrm{ka})$ in the planktonic $\delta^{18} \mathrm{O}$ record, the two data sets are plotted on their own timescales and are aligned at the time of the abrupt changes observed in each set of data. The date of the abrupt changes in the $\delta^{18} \mathrm{O}$ data is defined as the time when the first sharp cooling occurs at the end of each interglacial period, corresponding to the age immediately before the first sharp increase of the $\delta^{18} \mathrm{O}$ signal. 


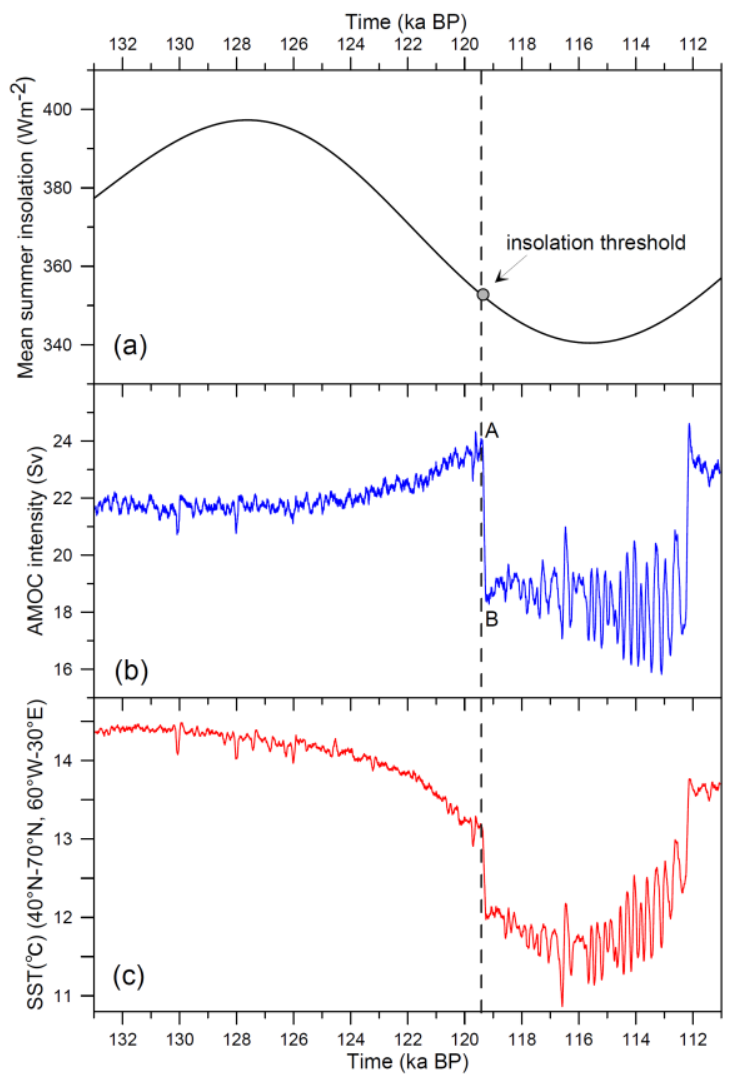

(d) Difference in sea surface temperature $\left({ }^{\circ} \mathrm{C}\right)$

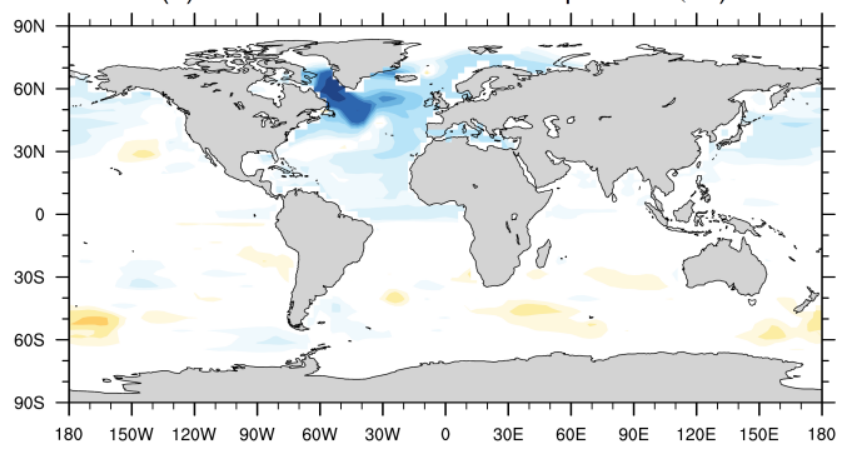

(e) Difference in surface air temperature $\left({ }^{\circ} \mathrm{C}\right)$

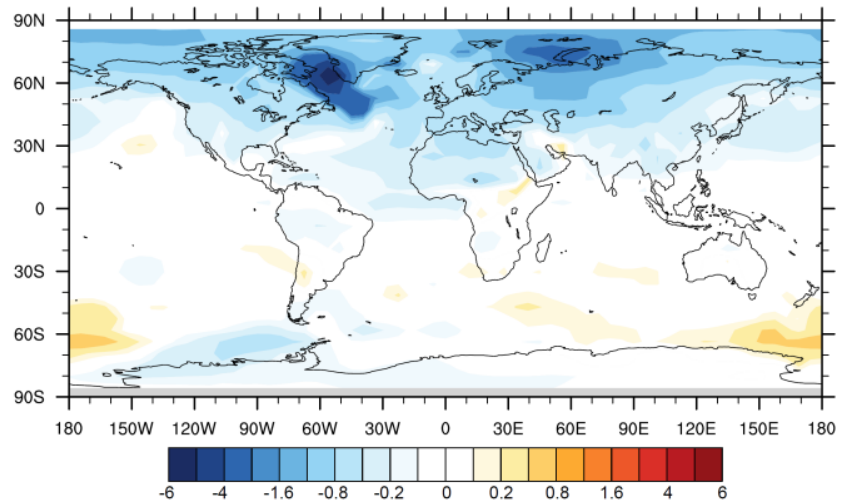

Fig. 2. Insolation-only induced variations in $A M O C$ and temperature during MIS-5e. (a) Mean summer insolation averaged over the four latitudes $55^{\circ} \mathrm{N}, 65^{\circ} \mathrm{N}, 75^{\circ} \mathrm{N}$ and $85^{\circ} \mathrm{N}(23)$; the mean insolation of the half-year $\mathrm{NH}$ astronomical summer is obtained by dividing the total irradiation received during the half-year summer (24) by the length of the half-year summer (25). (b) AMOC intensity; (c) annual mean SST in the North Atlantic region; (d) difference in annual mean SST between points $\mathrm{B}$ and $\mathrm{A}$; and (e) difference in annual surface air temperature between points $\mathrm{B}$ and A. The results are from the simulation with only insolation varying and $\mathrm{CO}_{2}$ fixed at $280 \mathrm{ppmv}$. 100-year running mean is applied on the simulated AMOC and SST. 


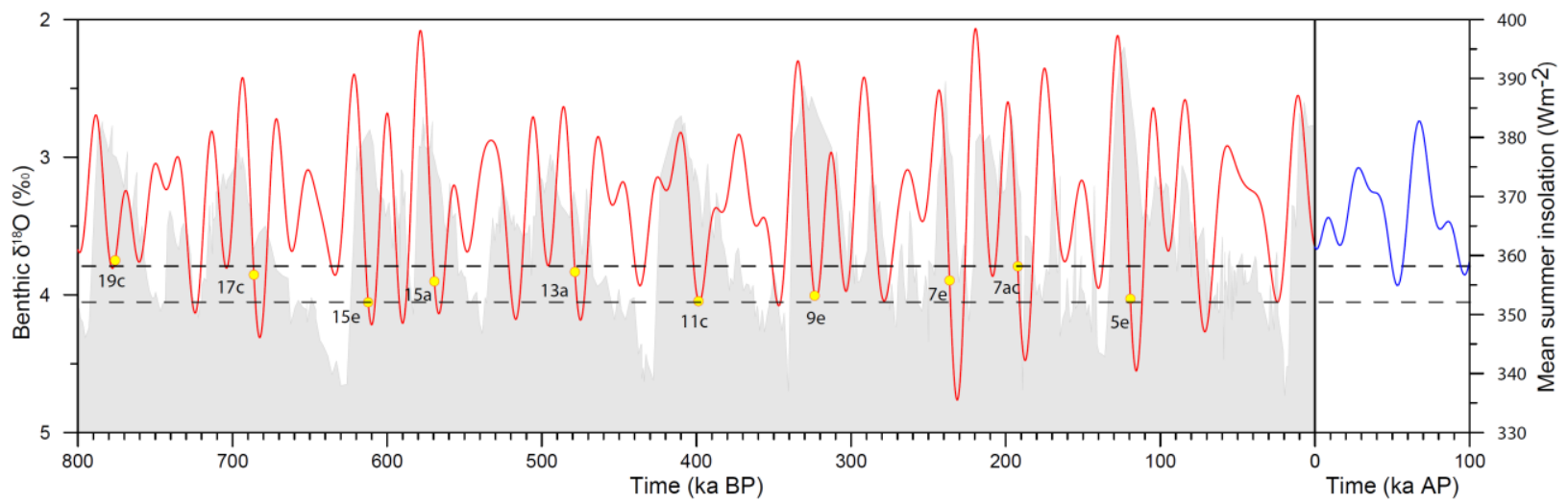

Fig.3. Insolation threshold band through the last $800 \mathrm{ka}$ and the future $100 \mathrm{ka}$. Red and blue curves are the mean summer insolation as defined in Fig.2. Gray shaded curve is the benthic $\delta^{18} \mathrm{O}$ at site $\mathrm{U} 1385$ (5) showing the glacial-intergalcial cycles. The two horizontal dash lines define the upper and lower insolation threshold values 358.2 and $352.1 \mathrm{Wm}^{-2}$ determined from the insolation-only simulations. Yellow dots indicate the times at the end of the interglacials when abrupt weakening of AMOC is triggered.
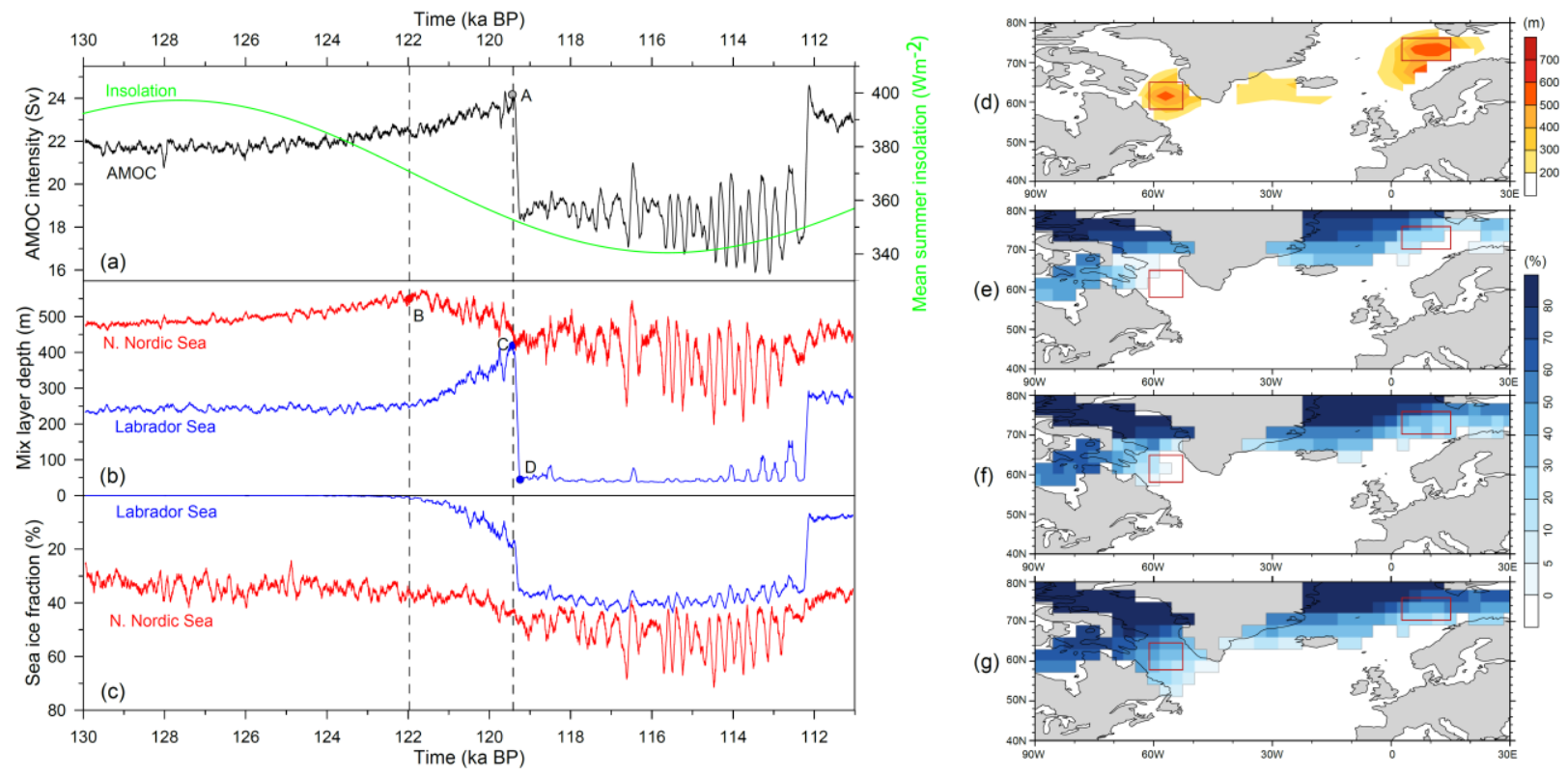

10 Fig. 4. Insolation-only induced variations in AMOC, the convection and sea ice in N. Nordic Sea and Labrador Sea during MIS-5e. (a) Mean summer insolation averaged over $55^{\circ} \mathrm{N}, 65^{\circ} \mathrm{N}, 75^{\circ} \mathrm{N}$ and $85^{\circ} \mathrm{N}$ (green) and AMOC intensity (black); (b) mix layer depth in the N. Nordic Sea $\left(70^{\circ} \mathrm{N}-\right.$ $\left.78^{\circ} \mathrm{N}, 2.5^{\circ} \mathrm{E}-17.5^{\circ} \mathrm{E}\right)$ (red) and the Labrador Sea $\left(56^{\circ} \mathrm{N}-66^{\circ} \mathrm{N}, 62^{\circ} \mathrm{W}-52^{\circ} \mathrm{W}\right)$ (blue); (c) sea ice fraction in the N. Nordic Sea (red) and the Labrador Sea (blue); (d) mix layer depth (m) at time A; (e), (f), (g) are sea ice fraction at time B, C and D, respectively. 100-year running mean is applied on the simulated results. The two rectangles in $(\mathrm{d})-(\mathrm{g})$ indicate the convection center in the Labrador Sea and the N. Nordic Sea. 